\title{
NEW RECORD OF THE ASIATIC WILDCAT (FELIS SILVESTRIS ORNATA GRAY 1830) IN NORTHEASTERN ANATOLIA
}

\author{
GÜNDOĞDU, E.* - SARI, A. - ARPACIK, A. - BAŞKAYA, Ş. \\ Department of Wildlife Ecology and Management, Faculty of Forestry, Karadeniz Technical \\ University, 61080 Trabzon, Turkey \\ (phone: +90-505-934-3200) \\ *Corresponding author \\ e-mail: ebubekirgundogdu@gmail.com \\ (Received $8^{\text {th }}$ Jul 2018; accepted $6^{\text {th }}$ Sep 2018)
}

\begin{abstract}
The aim of this study is to determine new distribution records of Asiatic wildcat in Northeastern Turkey. Latest distribution and status of this elusive cat was uncertain due to limited wildlife research in Turkey. This study was conducted in 2015 and 2016. Field studies were carried out based on direct and indirect observations. Besides obtaining camera trap photos, direct observations were conducted by one or two teams, each of which consisting of two wildlife experts. In indirect observations, all tracks, feces, spaw, scrape, urine and food remains were benefited from. As a result of the study, 6 camera trap video records belonging to Asiatic wildcat were obtained. Asiatic wildcat, once regarded as least concern species, is declining rapidly in its natural habitat because of habitat fragmentation followed by the pressure of large predators and excessive use of agricultural pesticides. This present study is an update on current distribution of Asiatic wildcat in Northeastern Anatolia of Turkey.
\end{abstract}

Keywords: distribution, camera trap, wildcat, Bingöl, Turkey

\section{Introduction}

There are twenty three recognized species of small wildcats worldwide (Yiqing and Yong, 1990; Nowell and Jackson, 1996; Jutzeler et al., 2010), being relatively primitive types and wild ancestors of domestic cats (Gao, 1987). Very simply, the European wildcat (Felis silvestris Schreber 1777) is distributed throughout Europe except for the northern regions; the African wildcat (F. s. libyca Forster 1780) is distributed in all African countries and south-western Asia; the Asiatic wildcat (F. s. ornata Gray 1830) is distributed in central and western Asia (Allen, 1938; Ellerman et al., 1951; Gao, 1987; Nowell and Jackson, 1996; Ablimit et al., 2010). The existence of distinguishable phenotypes across this wide distribution, along with apparently considerable local variation (Pocock, 1951; Yamaguchi et al., 2015), has left wildcat taxonomy in a state of confusion for many years (Guggisberg, 1975). The wildcat is a polytypic species with three wild subspecies, the European, African and Asiatic wildcats (Ragni and Randi, 1986, 1991; Wozencraft, 1993; Johnson and O’Brien, 1997). African and European wildcats are closely related and split recently, probably towards the end of the Last Glacial Maximum, as suggested by paleontological, biochemical and molecular data (Davis, 1987; Randi and Ragni, 1991; Masuda et al., 1996). Nowell and Jackson (1994) divided wildcats into three different forms; these three wildcat species seem to be more of a division of subspecies.

Domestic and wildcats can hybridize and generate fertile offspring both in captivity and in nature (Robinson, 1977; Ragni, 1993; Pierpaoli et al., 2003). The wildcats are now distributed worldwide due to deforestation, the spread of agriculture and the eradication of large predators, which have probably favoured the expansion of free- 
ranging, often in sympatry with wildcat populations in Europe and Africa (Nowell and Jackson, 1996).

There are five members of the Felidae family cat species in Turkey. Those are Leopard (Panthera pardus), European wildcat (Felis silvestris), Jungle cat (Felis chaus), Lynx (Lynx lynx) and Caracal (Caracal caracal) (Sar1, 2018). However, ecology, taxonomy, latest status and correct distribution and population sizes of those species are uncertain due to limited wildlife researches. The present research provided a new distribution record of the Asiatic wildcat in a narrow area of Turkey.

\section{Materials and methods}

\section{Study area}

Study area is located in Yedisu county of Bingöl province $\left(39^{\circ} 23^{\prime} 52^{\prime} \mathrm{N}\right.$; 40³6'39'E) in Northeastern Anatolia, Turkey (Fig. 1). Our main goals were to obtain distribution records of Asiatic wildcat from both Turkish and foreign literature and observed by local hunters, wildlife officers and unconfirmed information provided by local people. Therefore, this area was chosen as the study area.

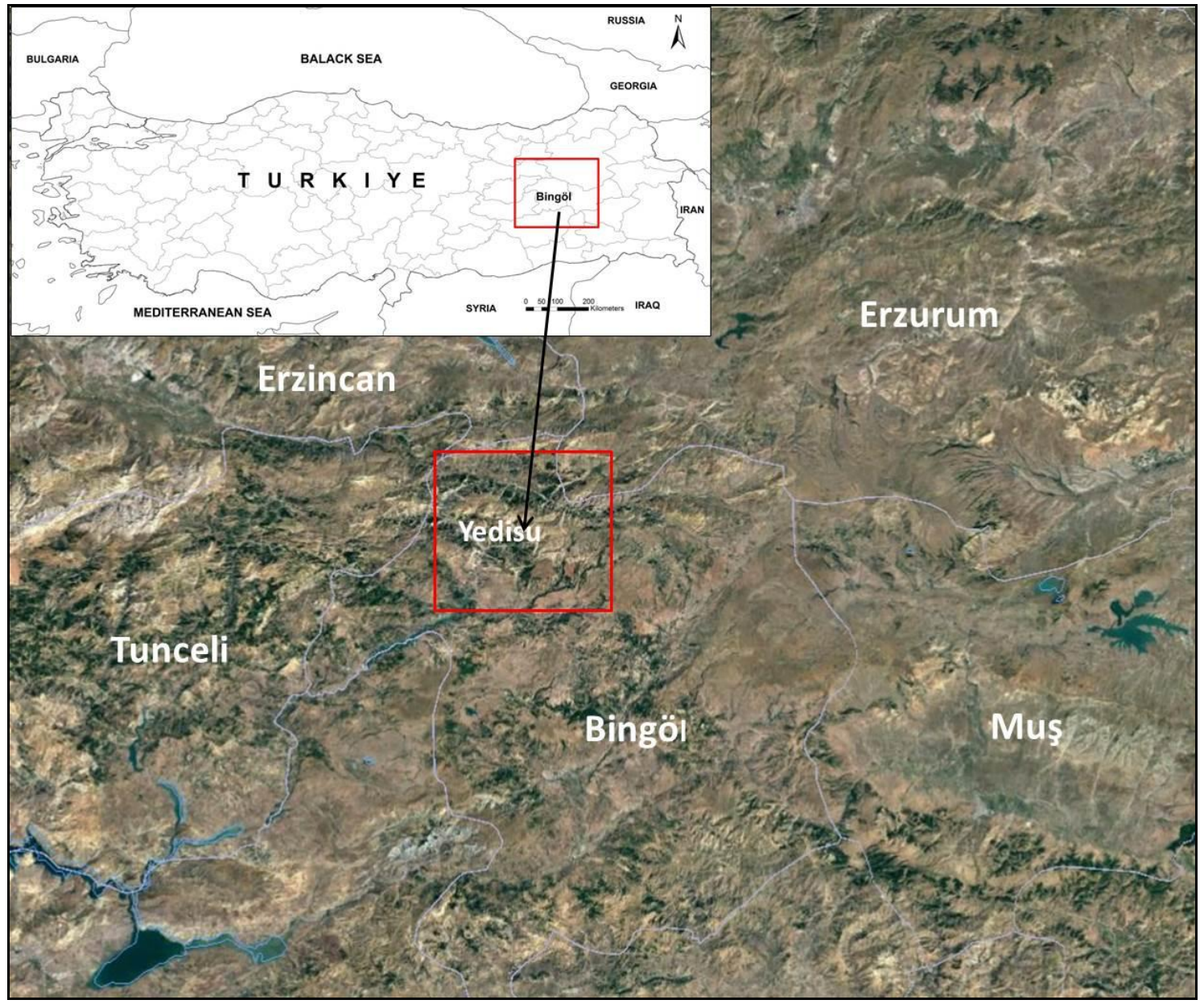

Figure 1. Location of study area (Google Earth, 2018) 
The land in the study area is quite rugged and high, with an average elevation of $1500 \mathrm{~m}$. Mountains and hilly areas occupy a very large space. The study area is surrounded by Çavuşlu Mountain (2660 m.) in the east, Devil Mountain (2950 m.) in the south, Bağır Mountain (3173 m.) in the west and Koşan Mountains (3078 m.) in the north. The heights of the high plateaus and plains on the mountains are not below $2000 \mathrm{~m}$. Even most plains are located on over $1000 \mathrm{~m}$ from sea level. The upper parts of the mountains cover the glacial lakes and the skirts cover moraine remains. On majority lands of Bingöl province, the dominant climate is continental. Winters are long and harsh, and summers short and hot. Annual mean temperature is $5.1^{\circ} \mathrm{C}$. Considering the course of temperature in the year, the coolest month is January $\left(-9^{\circ} \mathrm{C}\right)$, while the hottest month is August $\left(39^{\circ} \mathrm{C}\right)$. Annual mean precipitation in Bingöl is $32.9 \mathrm{~mm}$. The study area is predominantly the Iranian-Turanian floristic region in terms of vegetation. For this reason, in the regions where the study areas are located, plant societies generally consist of forest and steppe formation. The mountains are covered with sparsely forested, with parts of the southern parts of the mountains are often empty. Scots pine (Pinus sylvestris) forests are pure and mixed with a sparse and fragmented spread in the average 1300-2000 m. Oak forests (Quercus sp.) are located in the lower part of $1200 \mathrm{~m}$, and Common aspen (Populus tremula) and Silver birch (Betula pendula) trees are covered also scattered fragments.

\section{Materials}

A total of 21 camera traps which have infrared features were used and placed along the line during the study (Fig. 2). Swarovski 10x42 LC binocular and ATS/STS 80 (HD) (20-60x) telescope were used for direct observation. Various digital cameras (3x optical zoom-5.0 Mega Pixels and 12x optical zoom-6.0 Mega Pixels) and video recorder (24x optical zoom) were used to take photographs of species, their habitats and to record observations. Global Positioning System (Magellan Explorist 500L) was employed to record the altitude and coordinates in the field. We also conducted interviews with national park officers, Turkish military services, villagers, and shepherds: field situation in the past, poaching, and whether the species of special interest to the local people was discussed.

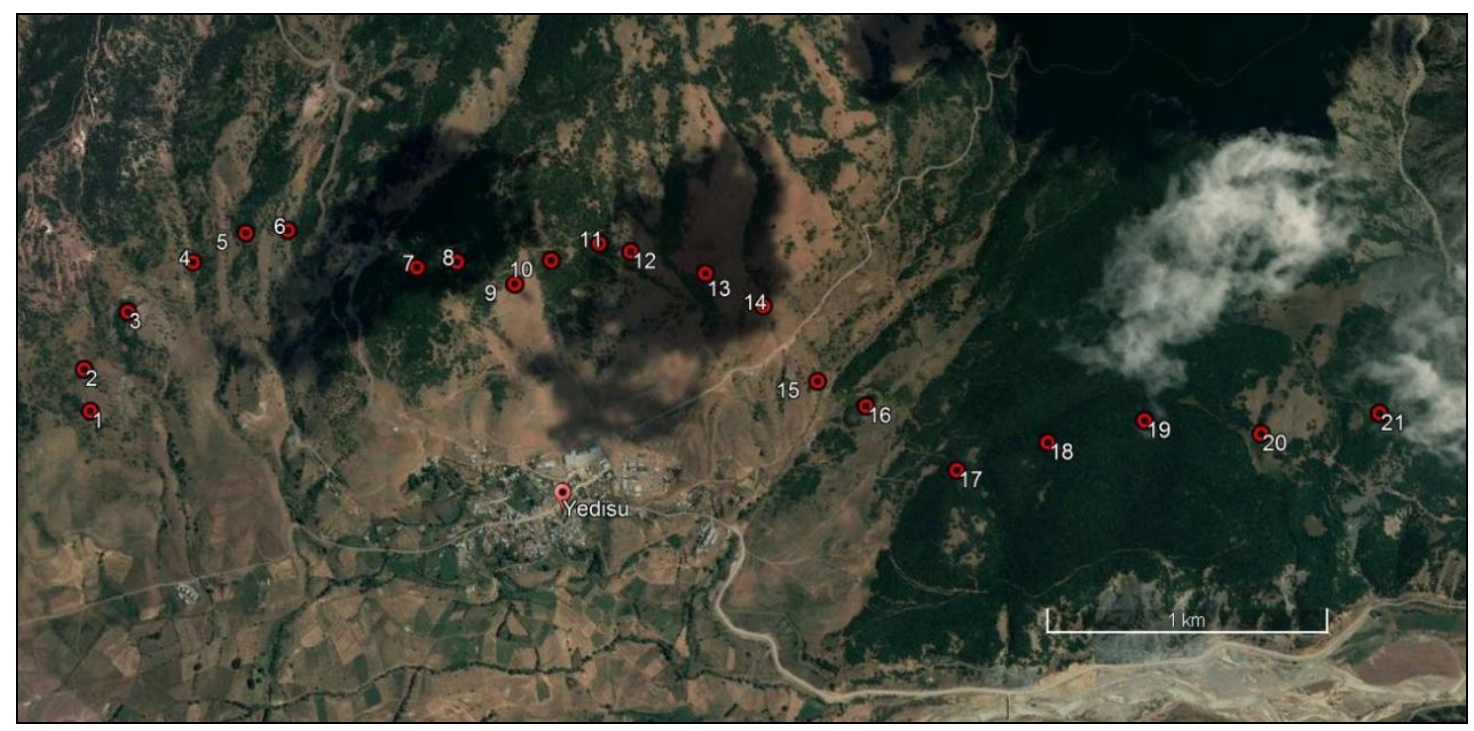

Figure 2. Location of 21 camera traps (Google Earth, 2018) 


\section{Methods}

Field studies were conducted in 2015 and 2016 within a $150 \mathrm{~km}^{2}$ area. We focused on making correct identifications of specimens and assessing the accuracy of observations by local hunters, wildlife officers and information provided by local people.

In external appearance Asiatic wildcat can only be confused with European wildcat, which has been characterized by its bushy tail, which ends as a broadly rounded black tip, and long soft fur with relatively conspicuous stripes (Yamaguchi et al., 2004). Asiatic wildcat has a slimmer build than European wildcat, a light brown or grey coloration with dark spots and a slim tail (Yamaguchi et al., 2004; Firouz, 2005; Yamaguchi et al., 2015). It was tried to obtain photographs and video images with camera traps in general. The camera traps were scattered randomly in the study area and were checked at certain times. The locations of camera traps were constantly changed according to tracks and indications obtained in the study area. Besides obtaining camera trap photos, direct observations were conducted by one or two teams, each of which consisting of two experts. In indirect observations, it was benefited from all tracks, feces, spaw, scrape, urine and food remains.

\section{Results and discussion}

Although specimens and living individuals of European wildcat have been reported in different parts of Turkey, The Asiatic wildcat records were obtained first in Yedisu, Bingöl in 2016 June. The Asiatic wildcat was only probably distributed in Northeastern of Turkey according to Demirsoy (1996). There is not any data about distribution of the Asiatic wild cat from Demirsoy (1996) in Turkey.

A total of 35625 photos and 161 hours of videos were recorded over 314 nights, making a total of 6594 trap nights for all the camera traps. As a result of the study 6 different camera trap video images belonging to one Asiatic wildcat were obtained. We checked all these data and found them to be $F$. s. ornata. Asiatic wildcat has distinct dark spots on its flanks as seen in the photos (Fig. 3). Our findings are in agreement with Ablimit and Khan (2013), that individuals identified in this study have a similar morphological structure with their findings. The coat pattern (color and points) of identified specimen are quite similar with them. Morphological criteria especially helped to resolve these identification problems in our study.

While European wildcats may be confused with domestic or feral cats, distinguishing them from Asiatic wildcat is easy. The wildcat's fur varies from tawny grey to light grey or sand colored, showing pronounced stripes and spots on the flanks, head and limbs, and also distinct rings on the black-tipped tail (Yamaguchi et al., 2004; Firouz, 2005). The European wildcat has been characterized by its bushy tail, which ends as a broadly rounded black tip, and long soft fur with relatively conspicuous stripes (Yamaguchi et al., 2015). The Asiatic wildcat is the least known and inhabits Eurasia from the Middle East to western India, through Central Asia to Mongolia and northwestern China. It is similar to the African wildcat, but is distinguishable by its coat pattern, which consists mainly of distinct dark spots instead of stripes. In most of the Middle East, including Iran, the Asiatic wildcat has spots on its flanks and head, while the coat of the European wild cat is uniformly greyish, without spots (Yamaguchi et al., 2004). 
Domestic and wildcats can interbreed and produce fertile offspring both in captivity and in nature (Robinson, 1977; Ragni, 1993; Pierpaoli et al., 2003). However, Randi and Ragni (1991) determined that the rate of hybridization of domestic cat and wild cats was very low and they used their own large gene pools in breeding. In this study, it is thought that Asiatic cat individuals not hybrid individuals from European wild cat and domestic cat. But this problem is planned to be revealed in the future with another genetic study.
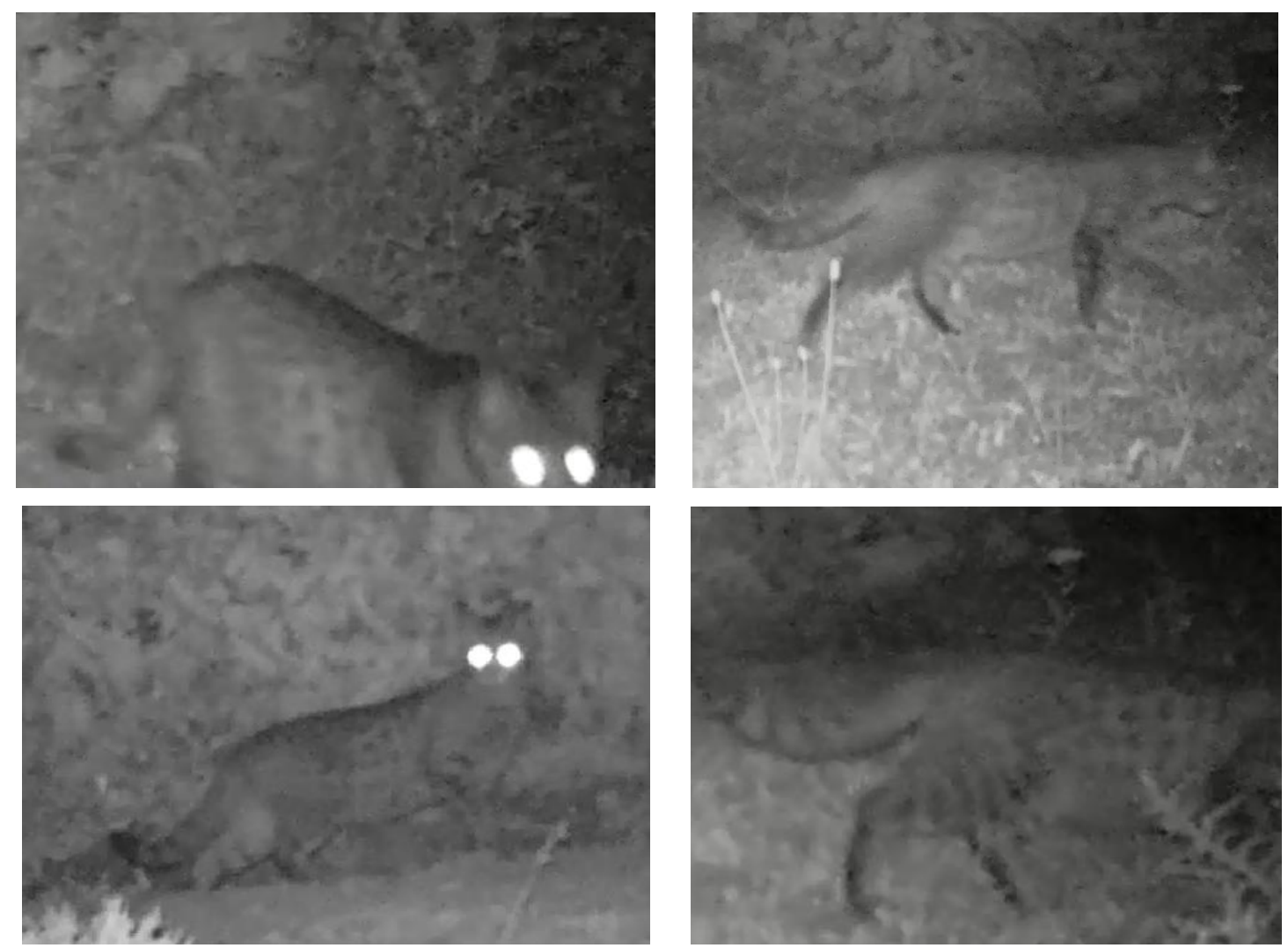

Figure 3. Camera-trapped video images Asiatic wildcat in the study area

Considering the habitat type characteristics of the areas belonging to the Asiatic wildcat, it has been determined that the important habitats are degraded Oak forest areas, rocky areas and pasture-grazing areas. These areas consist of grift shrub and trees and steep rocks. This habitat structure provides a number of concealed and escaped areas that can protect the Asiatic wildcat from larger compete predators such as leopard, lynx, wolf and bear.

There is limited information on the seasonal habitat use of Asiatic wildcat. However, it seems that the habitat use of the animal is strongly associated with the movements of its prey and human disturbance. Deforestation, the spread of agriculture and the eradication of large predators have probably favoured the expansion of free-ranging and feral cats, which are now distributed worldwide, often in sympatry with wildcat populations in Europe and Africa (Nowell and Jackson, 1996). The most important threats observed in the study for Asiatic wildcat are the habitat deterioration caused by overgrazing activities and the predatory pressure created by stray dogs and larger carnivore species. 


\section{Conclusions}

In Turkey, wildlife studies on mammalian species are still not enough. This is the first documented report of the Asiatic wildcat's distribution from Turkey. As a conclusion, Northeastern Turkey should be thoroughly and regularly studied in order to better understand the Asiatic wildcat status and develop urgent conservation measures in these areas. It is important that further work be carried out to ascertain the size of the remaining Asiatic wildcat population in the other parts of Turkey. Despite the small size of the forest, the area is still rich in both fauna especially rodents and flora. It was observed that the populations of species that may be a food source for the Asiatic wildcat such as European hedgehog (Erinaceus concolor Martin 1837), European hare (Lepus europaeus Pallas 1778), Common Tortoise (Testudo graeca Linnaeus 1758) and Williams's jerboa (Allactaga williamsi Thomas 1897) were in very good condition. The Asiatic wildcat being the predator, has an important role in maintaining the health of the ecosystem. Therefore, the population size of the Asiatic wildcat could be used as indicator of sustainable conservation and management of the species in the area. Unknown and population size is critically small, any fatality of Asiatic wildcat individuals may lead to population extinction in the study area. Therefore, more studies should be carried out to investigate the reproduction status and sex composition of the Asiatic wildcat population in the study area. This would help the managers to control the population size over successive years using suitable management techniques.

\section{REFERENCES}

[1] Ablimit, A., Khan, B. (2013): Status of Asiatic wild cat and its habitat in Xinjiang Tarim Basin, China. - Open J. Ecology 3(8): 551-558.

[2] Ablimit, A., Khan, B., Masuda, R., Ohdachi, S. (2010): Asiatic wild cat (Felis silvestris ornata) is no more a 'Least Concern' species in Xinjiang, China. - Pakistan J. Wildlife 1(2): 57-63.

[3] Allen, G. M. (1938): The mammals of China and Mongolia. - National History of Central Asia 11(1): 312-489.

[4] Davis, S. J. (1987): The Archaeology of Animals. - BT Batsford Ltd., London.

[5] Demirsoy, A. (1996): Turkey's Vertebrates-Mammalians. - Ministry of Forestry: Project No: 90 K 1000: 90.

[6] Ellerman, J. R., Morrison-Scott, R. C. S. (1951): Checklist of Palearctic and Indian Mammals. - British National History Museum, London.

[7] Firouz, E. (2005): The Complete Fauna of Iran. - Tauris, London.

[8] Gao, Y. (1987): Fauna Sinica: Mammalia, Vol 8: Carnivora. - China Scientific Press, Beijing.

[9] Guggisberg, C. W. A. (1975): Wild Cats of the World. - David \& Charles, London.

[10] Johnson, W. E., O'Brien, S. J. (1997): Phylogenetic reconstruction of the Felidae using 16S rRNA and NADH-5 mitochondrial genes. - Journal of Molecular Evolution 44: 98116.

[11] Jutzeler, E., Xie, Y., Vogt, K. (2010): Asian wildcat (Felis silvestris ornata). - Cat News Special Issue 5: 42-43.

[12] Masuda, R., Lopez, J. V., Slattery, J. P., Yuhki, N., O’Brien, S. J. (1996): Molecular phylogeny of mitochondrial cytochrome $b$ and $12 \mathrm{~S}$ rRNA sequences in the Felidae: ocelot and domestic cat lineages. - Molecular Phylogenetics and Evolution 6: 351-365.

[13] Nowell, K., Jackson, P. (1996): Wild Cats: Status, Survey and Conservation Action Plan. - IUCN/Species Survival Commission Cat Specialist Group, Gland, Switzerland. 
[14] Pierpaoli, M., Biro, Z. S., Herrmann, M., Hupe, K., Fernandes, M., Ragni, B. (2003): Genetic distinction of wildcat (Felis silvestris) populations in Europe, and hybridisation with domestic cats in Hungary. - Mol. Ecol. 12: 2585-2598.

[15] Pocock, R. I. (1951): Catalogue of the Genus Felis. - British Museum, London.

[16] Ragni, B. (1993): Status and Conservation of the Wildcat in Italy. - In: Seminar on the Biology and Conservation of the Wildcat (Felis silvestris), Nancy, France, 23-25 September 1992, Council of Europe, Environmental Encounters 16: 40-41.

[17] Ragni, B., Randi, E. (1986): Multivariate analysis of chraniometric characters in European wildcat, domestic cat and African wild cat (genus Felis). - Zeitschrift für Säugetierkunde 51: 243-251.

[18] Randi, E., Ragni, B. (1991): Genetic variability and biochemical systematics of domestic and wild cat populations (Felis silvestris: Felidae). - Journal of Mam. 72: 79-88.

[19] Robinson, R. (1977): Genetics for Cat Breeders. 2nd ed. - Pergamon Press, Oxford.

[20] Sar1, A. (2018): Habitat Use of Leopard (Panthera pardus) in Northeastern Anatolia. Doctorate Thesis. K. T. Ü. Graduate School of Natural and Applied Sciences, Department of Forest Engineering, Trabzon.

[21] Wozencraft, W. C. (1993): Felidae. - In: Wilson, D. E., Reeder, D. M. (eds) Mammal Species of the World: A Taxonomic and Geographic Reference. Smithsonian Institution Press, Washington and London, pp. 290-291.

[22] Yamaguchi, N., Driscoll, C. A., Kitchener, A. C., Ward, J. M., Macdonald, D. W. (2004): Craniological differentiation between European wildcats (Felis silvestris silvestris), African wildcats (F. s. lybica) and Asian wildcats (F. s. ornata): implications for their evolution and conservation. - Biol J Linn Soc 83: 47-63.

[23] Yamaguchi, N., Kitchener, A. C., Driscoll, C. A. (2015): Felis silvestris. - The IUCN Red List of Threatened Species, Gland.

[24] Yiqing, M., Yong, M. (1990): On the protection status of cats (Felidae). - Wildl. of China 4: 7-9. 